R. Histortn, Sto Paulo, n. 127-128, p. 53-68, ago-dea/92 a jan-jul/93.

\title{
MORTALIDADE E MORBIDADE DA CIDADE DO RIO DE JANEIRO IMPERIAL
}

\begin{abstract}
Maria Luiza Marcllio*
isk

RESUMO: Trata o artigo dos primeiros resultedos de um Projeto de pesquisa sobre a "Historia Social da Satde no Brasil (scculos 18 e 19)" que estamos desenvolvendo.

Contextualizamos sumariamente as condiçós sańitárias do Rio de Janeino, durante o Imperio e a agăo do Governo e da Academia Imperial de Medicina.

Calculamos os alveis de mortalidade geral e diferencial (livres e escravos e mortalidade infantil). Descobrimos que anualmènte e ate o final do seculo, a mortalidade foi inferior à natalidade. $O$ movimento sazonal mostrou-nos que as meses quentes e úmidos eram os de maior mortandade.

Enfim, procuramos mapear a cronologia das grandes epidemias que assolaram a populaço carioca no seculo passado e conhecer as principais moletias cronicas mais mortfferas. A tuberculase pujmonar por si 86 foi responsável por cerca de $15 \%$ das mortes em todo o periodo.
\end{abstract}

PALAVRAS-CHAVE: Mortalidade, Morbidade, Demografia, Rlo de Janeiro, Perfodo Imperial.

\section{CONDIÇŌES PROPICIAS PARA UM QUADRO DE MORBIDADE ELEVADA}

Entre os diplomatas da carreira da Europa do século passado diz-se que o pior castigo era sua designação para servir na cidade do Rio de Janetro. Compreende-se o horror que a cidade lhes causava, onde apesar das belezas naturais inegáveis, o estrangeiro deveria se defrontar com um quadro sanitário e de saúde pública tenebroso.

Sistematicamente, ano após ano, pelo menos depois dos anos $1830 \mathrm{e}$ até os primeiros anos do século atual, o número de óbitos superava de longe o dos nascimentos. A relação chegou a atingir em anos de aguda crise de mortalidade, como $o$ ano de 1850 , ano da entrada da febre-amarela na cidade, a cifra de 11.192 mortes para 5.817 nascimentos; ou ainda o ano de 1855 , quando chega pela orimeira vez o colera-morbo, quando foram registrados 11.180 mortos para apenas 6.660 nascimentos. Mas em anos digamos "nor- 
MARChLO, Maria Luba. Mortalidade e morbidade da cidade do Rio de Janeiro imperial.

mais" de mortalidade, morrem mais moradores do que nascem. Em 1840, por exemplo para 5.372 nascimentos registram-se 6.760 mortes (ver tabela $)$.

A população moradora no Rio de Janeiro aprendeu a conviver diariamente com a morte, a morte crónica e a epidemica. Chega a ser difícil para nós hoje entender como faziam para viver as pessoas do Rio de Janeiro face às múltiplas doenças infecto-contagiosas e epidemicas que as atacavam conjuntamente, a cada ano. No periodo de 1851 a 1860 , por exemplo, de acordo com as declaraçōes do médico da época Dr. Pereira Rego, 40 epidemias atingiram a população da cidade e outras 18 no decênio de 1861 a $1870^{1}$.

E bem verdade que autoridades médicas e governamentais tentaram modificar esse quadro, ao longo do século. Sua ação foi no entanto insuficiente e muitas vezes até inoperante.

Já em 1808, quando aqui chega a corte portuguesa com $D$. João, o príncipe regente, impressionado com o estado sanitário da cidade pede ao recém nomeado Físico-Mor Manoel Vieira da Silva a opinião dos médicos sobre as causas de tantas doenças e os meios de combate-las.

A resposta do Físico-Mor contém um esboço de uma política sanitária para a ciđade. Distingue, inicialmente, as causas naturais das não naturais. $O$ ar diz o Físico-Mor, é o principal causador de doenças. A contaminação do ar se dá pelas águas estagnadas nos pântanos que levam à putrefação de matérias organicas e vegetais, gerando gazes pestilentos, dá a necessidade de trabalhos de urbanização como aterro de pântanos, encanamento de águas, alargamento de ruas. Continua afirmando que as sepulturas nas igrejas e cemitérios da Santa Casa onde os corpos amontoados permanecem quase a descoberto infeccionam o ar da cidade. Propõe então, a criação de cemitérios fora da cidade com sepulturas individuais ou de no máximo tres corpos. A alimentação é outra causa das doenças. Começa pelo mau estado de conservação e vendas de carnes, peixes, farinhas, vinhos, vinagres e azeites. $O$ comercio, os matadouros, os açougues devem ser controlados. Enfim o porto é outro ponto produtor de doenças e mortes. Aconselha-se a criação de um lazareto para a quarentena de escravos recém chegados e portadores de moléstias contagiosas e cutâneas ${ }^{2}$.

1 PEREIRA REGO, Dr. José Esboço histórico das epidemias que tem grassado na cidade do Rio de Janeiro: Typographia Nacional, 1872, p. 210.

2 SILVA, Manoel Vieira Reflexöes sobre alguns dos meios propostos por mais confízentes para melhorar o elima da cidade do Rio de Janeira, 1808. Ver ainda: Dr. SIGAUD. Du climat et des maladies du Brísil. 1844. 
R. Htst6rto, Såo Paulo, n. 127-128, p. 53-68, ago-dez/92 a jan-jul/93.

Em 1810 cria-se o Instituto Vacínico e o Ensino Cirúrgico (1813) para o "restabelecimento da saúde do povo". Este foi o embrião da futura Escola Imperial de Medicina do Rio de Janeiro, criada em 1832.

$O$ velho poder médico português desaparece em 1828 , sendo extintos os cargos de Físico-Mor (poder arbitrário e inoperante) e de Cirurgiăo Mor do Império.

As Câmaras Municipais passam a ser responsáveis pela saúde e higiene pública locais.

Surge em 1829, a Sociedade de Medicina e Cirúrgica do Riơđe Janeiro como ofensiva do corpo médico, na tentativa de impor, défender e normalizar a Medicina, dando início assim, à medicina social e preventfva'brasileiras e sua luta contra o charlatanismo e o curandeirismo. Em 1855, a Sociedade transformou-se em Academia Imperial de Medicina, com o apoio oficial do governo regencial.

Mas é a terrível epidemia da febre-amarela que matou mais de 4 mil pessoas que provocará profundas mudanças na política de saụ́de do Império.

$O$ ministério do Império assume o comando da saúde pública e pede à Academia de medicina a elaboração de um plano para combater o terrivel mal que matou principalmente as categorias mais abastadas da cidade. Em 1850, os médicos propõem:

ie:

1 - a criação de uma Comissâo Central de Saúde Pública, para coordenar o combate à epidemia;

2 - a divisão da cidade em paróquias e distritos com comissões paroquiais de Saúde Pública compostas de subdelegados, fiscais e de trés médicos;

3 - a criação de um serviço de assistência gratuita aos pobres, com médicas, remédios, dietas, etc.;

4 - assistencia sanitária pelas comissóes, a navios, mercados, prisoes, hospitais, conventos, colégios, quartéis, teatros, igrejas, etc., velando pelo seu bom estado de higiene;

5 - registro médico.

Daí saiu a Junta Central de Higiene Pública que será mantida até quase o final do século.

Em 1886, a junta transformou-se na Inspetoria Geral da Higiene e foi criada a Inspetoria Geral da Saúde dos Portos, ambos orgãos medicos. 
MARCiLIO, Maria Lotea. Mortalidade e mortidade da cidade do Rio de Janetro imperial.

Apesar da ação do corpo médico, as medidas governamentais foram ineficazes para reverter o quadro da situação sanitária do Rio de Janeiro, no século XIX.

Comprovam esta afirmaçáo os níveis elevadíssimos de mortalidade geral e diferencial da cidade em todo o século. Para os anos de censo, a mortalidade bruta foi de $55 \%$ em 1838 e de $40 \%$ em 1871 . Diferenciando-se esses niveis pelos dois segmentos, mais importantes da sociedade, os níveis eram, em 1838, de $47 \%$ para os livres e de $66 \%$ para os escravos. Em 1871 , essas taxas foram de $39 \%$ e de $41 \%$ respectivamente (O ano de 1871 , foi um ano de trégua epidémica).

E bem verdade que, o flagelo que se abateu sobre a populaçăo em 1850 provocou a tomada de várias medidas de caráter de saneamento básico e de higiene pública. Pântanos sáo secados, os limites da cidade săo ampliados, abrem-se novas ruas, são construídas inúmeras edificaçōes e residências, nos locais mais salubres e em meio à mata atlantica dos morros săo instaladas novas moradias, abrem-se valetas por todos os lados para a canalização de esgotos, melhora o abastecimento de água, são definitivamente proibidos os enterramentos em igrejas e consequentemente são construidos cemitérios públicos, estabelece-se um hospital de isolamento fora do centro, além de outras medidas.

Apesar de tudo, estas medidas mostraram-se insuficientes. A cidade nåo parava đe crescer com a grande entrada de escravos da África (entre 1830 e 1850) e a seguir de escravos de outras províncias, com o aumento contínuo da população européia e de outras partes do pais, determinando um desenvolvimento urbano sem precedentes das atividades portuárias e um crescimento acelerado dos setores secundário e sobretudo terciário da economia da cidade. Esse crescimento demográfico, pode ser visto através dos poucos censos existentes para a cidade, ao longo do século.

\section{POPULAÇĀO DA CIDADE DO RIO DE JANEIRO}

$\begin{array}{lrrr}\text { Anos } & \text { Livres } & \text { Escravos } & \text { Populaçăo } \\ 1799 & - & - & 42.168 \\ 1821 & 57.605 & 55.090 & 112.695 \\ 1838 & 97.162 & 39.916 & 137.078 \\ 1849 & 155.864 & 110.302 & 266.466 \\ 1870 & - & - & 235.381 \\ 1890 & - & - & 522.651 \\ 1906 & - & - & 811.443\end{array}$

Fontes: Arquivo Nacional do Rio de Jaceiro, cod. 808 lv. fl. 17v; Relatório do Ministério do Império 1838 e 1871 e Recenseamento do Rio de Janeiro realizado em 20 de setembro de 1906. Rio de Janeiro, Officina de Estatistica, 1907. 
R. Hist6ria, Sho Paulo, n. 127-128, p. 53-68, ago-dea/92 a jan-jul/93.

Esse acelerado crescimento demográfico da Corte do Rio de Janeiro no século passado acarretou, no setor de urbanização e da saúde pública especialmente, problemas graves que náo puderam ser controlados pelas medidas governamentais e médico-sanitárias tomadas e nem pelas condiçōes de desenvolvimento da própria Medicina da Época.

Embora ampliados os limites urbanos, construidas novas casas de moradia por todo lado, melhorados os sistemas de esgotos e de água potáyel faltavam casas para a população especialmente para os setores mais destituidos da sociedade. Daí a formação mais acelerada de cortiços nos locals aterrados só com imundicies, onde se amontoavam numerosas faḿlias em construções precárias, origem das conhecidas favelas do Rio.

$O$ abastecimento de carnes e alimentos torna-se cada vez mais problemático, contribuindo para o desenvolvimento de doenças de todo tipo, a começar pela tuberculose e pelas diarréias mortfferas, alem das facilidades que a promiscuidade, a sujeira, a contaminação de águas e alimentos, etc., criavam para a propagação das epidemias.

\section{UMA MORTALIDADE CONSTANTEMENTE MAIOR QUE A NATALIDADE}

Pelo menos dentre os estudos de mortalidade realizados para o Brasil antes de 1900 , não se conhece fenômenos de mortalidade semelhantes ao do Rio de Janeiro ao longo de um período de quase 80 anos! Uma mortalidade elevadíssima e constantemente maior que a natalidade.

O crescimento natural da população, sempre negativo, só conseguiu equilibrar-se e torna-se positivo a partir do início do século $\mathrm{XX}$, com as medidas de saneamento realizadas por Oswaldo Cruz. Em 1903 ainda, para 18.061 nascidos na ciđade foram contados 19.308 mortos. Em 1905, já se notam os reflexos do plano do Dr. Cruz, pois contra 20.228 nascidos, morreram 17.386 pessoas. Daf para frente, salvo alguns poucos anos excepcionais de crise de mortalidade, os óbitos mostram tendencias contínuas de queda média de $19 \%$ de mortalidade para $26 \%$ de natalidade geral, até cerca de $1940^{3}$. 
MARCII10, Meria Loime Mortalidede e motbidade da cidade do Rto de Iaseiro imperial.

\section{GRÁFICO I}

Bvoluçáo da Mortalidade e da Natalidade no Rio de Janeiro 1835/1884

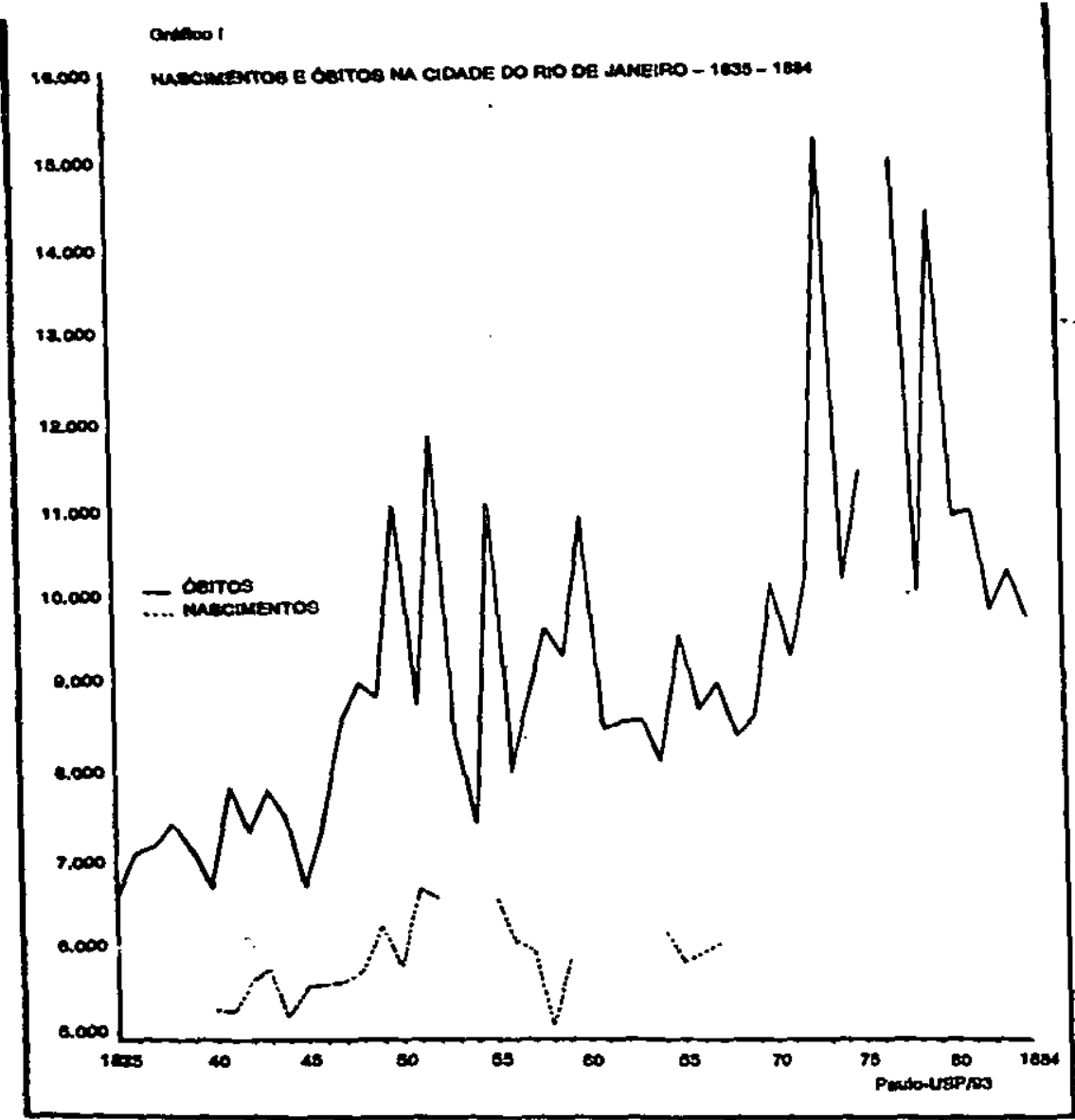


R. Historta, Sto Paulo, n. 127-128, p. 53-68, aga-dez/92 a jan-jul/93.

Os dados disponíveis permitem-nos alguns cálculos sobre a mortalidade infantil. Em 1859, os bebes que morreram antes de completar um ano de vida apresentaram uma taxa de 359\%o; os que faleceram antes dos 5 anos a taxa foi de $604 \%$ o. Em 1864 a mortalidade infantil foi de 206; cm 1873. do 578; em 1875 de 645 e em 1877 de 604 para cada mil nascidos. Ora, se de $40 \%$ a $60 \%$ das crianças que nasciam morriam ate os 12 meses, e se $60 \%$ c mais delas não ultrapassavam a faixa etária de 5 anos podemos, por ar s6, aferir sobre as terriveis condições sócio-economicas e sanitárias da população carioca. Um verdadeiro genocídio de crianças ocorria anualmente na cidade Imperial do Rio de Janeiro.

Essa mortalidade, teve sempre maior incidencia durante os meses. quentes e chuvosos de janeìro, fevereiro e março, quando segundo os relatos ocorriam, não só grandes estragos pelas desinterias e febres de todo tipo, mas era quando mais atacavam as epidemias.

Movimento sazonal das mortes: 1858 - 1867 populocto garm $n^{2}$ absoluto $\quad n^{*}$ p/dia e dikrios
proporelonito

$\begin{array}{lrrrr}\text { Jan } & 7.655 & 246,9 & 119 \\ \text { Fev } & 6.620 & 234,3 & 113 \\ \text { Mar } & 7.406 & 238,9 & 115 \\ \text { Abr } & 6.653 & 221,8 & 107 \\ \text { Mai } & 6.526 & 210,5 & 101 \\ \text { Jun } & 6.416 & 213,9 & 103 \\ \text { Jul } & 5.543 & 178,8 & 86 \\ \text { Ago } & 5.480 & 176,8 & 85 \\ \text { Set } & 5.232 & 174,4 & 84 \\ \text { Out } & 5.809 & 187,4 & 90 \\ \text { Nov } & 6.219 & 207,1 & 99 \\ \text { Dez } & 6.344 & 204,6 & 98 \\ \text { Total } & 75.898 & 2.495,4 & 1.200\end{array}$

Fontes: Relatorios anuais do Ministćrio do Império. Falta aperas o ano de 1862. 
MARCiLIO, Maria Luiza. Martalidade e morbidade da cidnde do Rio de Janeiro imperial.

\section{GRÁFICO II}

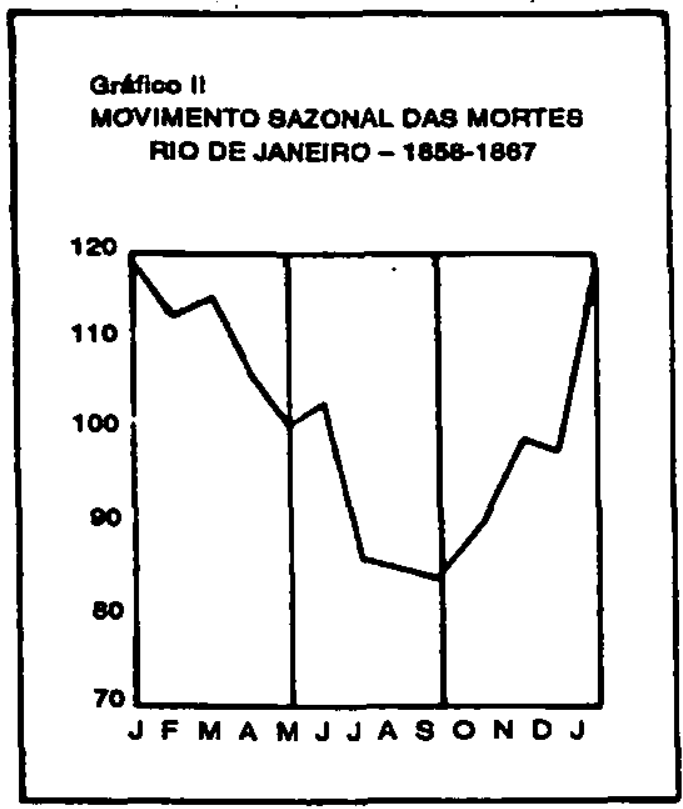

Pauto-uspros

\section{EPIDEMIAS E ENDEMIAS NO RIO DE JANEIRO IMPERIAL}

O estudo sistemático da morbidade antiga no Rio de Janeiro apresenta algumas dificuldades de ordem metodológica, de organização e de interpretaçăo dos dados disponiveis.

A primeira dificuldade refere-se às estatísticas vitais que foram produzidas por diferentes serviços públicos ao longo do século ${ }^{4}$. Estas fontes

4 Os dedos que utilizamos foram os publicados nos: Relatórios anuais apresentados pelo Ministero dos Negdios do Império a Assembleia Legislativa Nacional a partir de 1835 e at6 1884; os recenseamentos e quadtos gerais da populacto do Imperio: Populagito do Provincia do Rito de Janeira, 1821. Arquivo Nacional do Rio de Janeing cod 808 fl. 16 v;; Mappa da Populayio do Municfpio da Corte de 1838. ANR, cod. 808, v.2; Recenseamento Geral do Municipio do Corte do mes de abril de 1870. ANRJ. cod 808, v.3; Brasil, Rio de Janeiro. Recenseamento de 1906. Rio de Janeiro, Officina de Bstatistica, 1907. Estas fortes foram complementadas pelo chra do mbetico: REGO, Jose Peseira, op.cit. 
R. Historta, Sto Paulo, n. 127-128, p. 53-68, ago-dez/92 a jan-jul/93.

apresentam-se de forma não uniforme. Assim, por exemplo, entre 1837 e 1853 os mapas dão-nos os totais de batizados, obitos e casamentos repartidos entre livres e escravos, por sexo e por paróquias. A partir de 1854 e ate 1858 ao lado desses mapas, são organizados outros dos enterros por cemitérios públicos, por mês e distinguindo-se os nacionais dos estrangeiros, os livres dos escravos e por sexo. Em 1859, as estatísticas mortuárias publicadas distinguem sexo, grupos etários, estado civil, livres e escravos e assinalam as doenças que mais mataram a população no ano. Este formato mantém-se até 1863. Em 1864 os quadros de mortalidade da cidade deixam de mencionar as doenças e as classificam por grandes setores, conservando a distinção de sexos, nacionalidade, condição social, grupos etários e distribuindo as mortes pelos meses do ano. Já a partir de 1869 , as estatísticas da morte obedecem à nova Classificação Internacional da Causa-mortis, conforme as deliberaçōes do Congresso Internacional de Estatística. Em cada grupo de causas da morte são discriminadas as respectivas doenças. Guardam-se as distinçōes de sexo, condição social, nacionalidade, idades agrupadas e acrescentam-se profissões, hospitais onde faleceram, paróquias e meses do ano. Mas a Classificação Internacional não é obedecida todos os anos, pois entre 1877 e 1879 só se definem as moléstias que ocasionaram as mortes e somente sua distribuição mensal, abandonando-se os đemais itens. Entre 1880 e 1882, as informações resumem-se apenas aos números de mortes por mes, sexo, condição social, nacionalidade e cinco grupos de idades. Nos anos de 1883 e 1884 os dados são por paróquias, sexo, estado civil, deixando-se a causa mortis.

A segunda dificuldade de análise, não menos complexa, refere-se aos nomes das doenças. Sabe-se que o conjunto das moléstias de um grupo humano tem uma história própria. O conhecimento que se tem das doenças muda: novo saber, novos nomes. Por outro lado, as doenças mudaram não somente de frequência, mas de natureza. Dal o risco de querer definir, sob um critério arcaico, a doença correspondente hoje ${ }^{5}$. Por exemplo, há mais de uma centena de títulos antigos para designar um sistema de febres (febre perniciosa, febre biliosa, febre pútrida, febre exantemática, febre tifóide, febre amarela, febre intermitente, febre renitente, etc.); por outro lado, há termos simples que designam sintomas que näo permitem nenhuma previsåo sobre a real causa da morte.

5 Ver sobre o assunto as reflexdes de DESAIVE, J.P. et alli. Medicins, climat et dpidemies d la fin du XVIIe siecle. Paris: Mouton, 1972, pp 146 e seguintes. 
MARCillo, Mria Loiza. Mortalidade e mortichde da cidade do Rio de Janieiro imperial.

Enfim, terceira e nāo menor das dificuldades de análise refere-se à definiçăo e determinaçäo das epidemias. A partir de que frequencia estatística anual de morte por uma doença contagiosa se pode considerar como sendo um ano epidemico? Ou deve-se considerar epidemia, um contágio generalizado de uma doença passageira, mesmo que não tenha adquirido proporções de mortalidade de crise? ${ }^{3}$

Estas dificuldades estāo longe de serem resolvidas neste trabalho inicial. Nossa pretensāo é apenas a de apresentar o quadro geral, endémico e epidemico da ciđade do Rio de Janeiro, com base nas informações preliminares que conseguimos reunir. Esse quadro é grave, agudo, por vezes catastrófico.

Para começar, queremos chamar a atenção de que ao lado das taxas elevadissimas de mortalidade infantil, das frequentes e quase anuais altas da curva da morte devidas a surtos epidémicos vários, a doença crónica que mais matou os habitantes do Rio de Janeiro em todo o período analisado foi a tuberculose pulmonar. Em média, e em todo o século cerca de $17 \%$ de todas as mortes foram ocasionadas pela "tísica", como se pode ver pelas estatísticas que reunimos para alguns anos do século.

\section{MORTES POR TUBERCULOSE PULMONAR DO RIO DE JANEIRO}

$\begin{array}{lcc}\text { Ano } & \text { Número } & \begin{array}{c}\text { \% sobre a Mortalidade } \\ \text { geral }\end{array} \\ 1859 & & \\ 1860 & 1458 & 14,8 \\ 1861 & 1498 & 13,6 \\ 1869 & 1321 & 15,2 \\ 1871 & 1596 & 18,3 \\ 1872 & 1773 & 18,9 \\ 1873 & 1511 & 14,6 \\ 1874 & 1626 & 10,6 \\ 1877 & 1656 & 14,3 \\ 1878 & 1802 & 11,9 \\ & 1888 & 18,6\end{array}$

Fonte: Relatórios do Ministério do Império. 
R. Historia, Så Paulo, n. 127-128, p. 53-68, ago-dez/92 a jan-jul/93.

Ainda dentro da categoria de moléstias vinham depois da tuberculose, as diarréias e desinterias, seguidas das febres, da bronco-pneumonia, do tétano, das doenças do coração, hepatites, sífilis, elefantíases, sarnas e parasitas intestinais dentre as mais frequentes.

A lista das moléstias epidémicas que atacaram os habitantes da cidade é vasta. Começa pela vaŕola e sarampo, passando pela febre-amarela, o cólera-rombo, a escarlatina, o crupe, a coqueluche, o tifo e a gripe.

Tentaremos reconstruir a cronologia das epidemias durante o imperio (1822-1889), até onde nossos dados puderam nos ajudar, procurando mostrar com isso o contexto altamente favorável para a propagação das doenças e da morte que foi a cidade do Rio de Janeiro de 1830 e até os primeiros anos do século atual.

Desde os fins do ano de 1828 assola o Rio de Janeiro uma forte epidemia chamada de Febre de Macacu (Município de onde se originou), que foi apresentada como de caráter tifoide e bilioso. Estas febres intermitentes invadem os municípios vizinhos de Magé, Guapi, Porto de Estrela, Pilar, Itomerim, Iguaçu e Irajá até o ano de 1834. Na cidade do Rio ela foi particularmente mortifera.

No ano de 1831 ao lado de generalizado contágio da epidemia de oftalmias (não mortífera, mas que ocasionou a cegueira em vasto número de pessoas), reinou com caráter grave a da coqueluche, complicada com pneumonias, resultando em forte mortalidade infantil.

No ano de 1834 , nos meses mais quentes, houve forte contágio de "febres renitentes e intermitentes de caráter gástrico, bilioso e desintérico. De julho em diante, foi a vez da varíola que volta em caráter epidemico de certa gravidade, com muitas vítimas, atacando de preferencia os recrutas, os escravos e os africanos.

A gripe surge em janeiro - fevereiro de 1835 , cessando em março, quando reaparecem as febres intermitentes, provavelmente de carater tifoide. De agosto ate o final do ano foi a vez da epidemia do sarampo, sem gravidade.

1836 foi um ano de grandes estragos com o aparecimento do tifo. "Importado incontestavelmente por um navio conduzindo para cima de 500 colonos vindos das Ilhas da Canárias... dura de junho a agosto". Ela foi de caráter local. Com ela, reinou o sarampo que atacou em todas as paroquias durante seis meses e ocasionou forte mortalidade.

No ano seguinte, volta a atacar o sarampo, extinguindo-se praticamente em abril. "Essa epidemia não respeitou idades, sexos, conđiçōes sociais, nem localidades: o rico como o pobre; as crianças como os adultos; os habitantes da cidade, como os do campo... sucumbindo número avultado de crianças de todas as classes" (REGO, p. 96). 
MARChLO, Maria Luiza. Mortalidade e morbidade da cidade do Rio de Janeiro imperial.

Em 1838, foram muitas as vitimas da bronco-pneumonia, especialmente entre os meses de abril a maio. E conforme o Dr. Pereira Rego: "O completo desleixo da higiene pública, como as más condiçōes da atmosfera, mais o comércio imoral e desumeno da escravidão" tornou a variola altamente destruidora de vidas nesse ano. A varfola invadiu os bairros da Prainha, Valongo, Saúde, Gamboa e Saco do Alferes atacando famílias inteiras e fazendo muitas vitimas, sobretudo entre crianças. Essa epidemia espalhou o terror e consternação entre todos os habitantes. Em outubro - novembro já estava debelada. Desta vez, os mais poupados foram os pobres e pretos escravos.

Os anos de 1839, 40 e 41 foram de trégua epidémica. Em 1842, o tifo ataca duramente a cidade, mas o surto foi o contágio da escarlatina matando sobretudo os jovens, escolhendo suas vitimas entre as classes mais abastadas da sociedade e as crianças. Os pobres e os pretos foram poupados. Aproximadamente mil pessoas faleceram e sua açāo đurou até julho de 1844 .

0 ano de 44 foi ainda 0 ano da epidemia da varfola e do sarampo e 1846 ate 48 a febre dita reumática, de forma benigna atingiu muitas pessoas.

Porém, uma das páginas mais negras na História das epidemias do Rio de Janeiro estava por vir. Desde os finais de 1849, mas sobretudo em 1850 chega ao Rio a terrivel epidemia da febre amarela.

O aumento da população e a entrada em escala elevada de navios negreiros no Rio, no ano de extinção do tráfico de escravos para o Brasil inscrevem-se entre os fatores que favoreceram a propagação da febre amarela. Mas as trágicas condições de higiene, os inúmeros pântanos da cidade, o lixo acumulado por toda a parte, ajudaram na multiplicação dos mosquitos transmissores e na devastadora propagação do mal.

Diz o Dr.Pereira Rego que: "Tal foi o terror que incutiu na população nos dias de seu maior reinado que ela, encarando-a como um castigo providencial, correu em massa aos templos, para dirigir preces ao Altissimo pela cessaçảo de tão devastador flagelo e saiu em procissão pelas ruas, orando no mesmo sentido. Ela atacou figuras das mais ilustres da província e membros das classes mais elevadas (REGO, p. 54).

A febre amarela veio da Bahia, por barcos e a Academia Imperial de Medicina incumbiu a Santa Casa de Misericordia de organizar hospitais e enfermarias provisórias em toda cidade. Foi nomeada uma comissão de oito membros da Academia e criadas comissóes médicas paroquiais para socorrer os doentes graves nos domićlios. Outras comissōes de polícias foram montadas no Porto para examinar navios que chegavam e recolher doentes $\mathrm{em}$ hospitais.

O Ministro do Império, Visconde de Monte Alegre, proibiu terminantemente o enterro de corpos nas igrejas, mandando-os para os cemitérios 
públicos. Nos hospitais e enfermarias improvisadas foram recolhidos 6.223 doentes, dos quais 4.630 se curaram e faleceram 1587. A mortalidade por febre amarela no ano foi de 4.160 , num total de 11.192 mortes em geral (37\% das mortes por febre amarela).

Para complicar o quadro nosológico da cidade, nesse mesmo ano a varíola ataca a população e com ela o sarampo também.

No ano seguinte continua a ação afastada da febre amarela, complicada com novos surtos epidemicos de coqueluche, varicela e foi ate maio, embora com caráter menos grave deixando um saldo de 471 vítimas. A coqueluche iniciou-se em fevereiro, generalizando-se até abril, atacando duramente a infancia. A varicela e o sarampo foram mais benignas com gravidade maior em outubro, devido a complicações com bronco-pneumonias e afecções cerebrais.

A febre amarela, em 1852 continuou matando. Foram 1.943 as vítimas no Rio, tendo como mês de maior incidencia, abril, quando fez $\mathbf{4 0 2}$ vítimas. No segundo semestre o sarampo reaparece em caráter epidemico, fazendo muitos doentes, mas com poucas vítimas.

Apesar de todos os melhoramentos realizados, as medidas foram insuficientes e a febre amarela continuou atacando e matando a população durante 10 anos.

Outro ano de terrível memória para a população da cidade foi o de 1855. Al, inaugurou-se no país o primeiro surto de colera-morbo, vindo da Europa através de navios britânicos e portugueses.

O primeiro porto brasileiro afetado foi o de Belém do Pará, em maio de 1855 , com a chegada da galera portuguesa Defensor, vinda da cidade do Porto com passageiros afetados do mal, dos quais 36 haviam morrido durante a viagem. A difusão na Província foi tão larga que em um ano contou-se cinco mil vítimas. Daí o mal propagou-se para a província do Amazonas.

O segundo ponto de entrada da epidemia, foi Salvador da Bahia, em março do mesmo ano através do Duque inglés Mercury S. John. Logo toda a Província foi atingida com incrível rapidez fazendo para mais de $\mathbf{3 0}$ mil vítimas.

O Rio de Janeiro foi o terceiro ponto, importando o mal pelo vapor $S$. Salvador que aí chegou em 11 de julho. Rapidamente o collera alastrou-se, atingindo o ponto máximo em novembro com uma mortalidade de 2.300 , número que nem mesmo a maior força da febre amarela conseguiu em 1850.

O governo mandou estabelecer em todas paróquias da cidade, postos médicos para recolher doentes pelas ruas, nomeou comissōes paroquiais para visitar doentes em domićlios, distribuiu esmolas levantadas junto à população. As mulheres de todas as categorias tiveram uma ação de voluntariado e 
MARCfLIO, Maria Laiza. Mortalidade e morbidade da cidade do Rio de Janeiro imperial.

atendimento aos doentes destacada. $O$ próprio Imperador saiu para visitar doentes pelos hospitais da cidade.

A epidemia espalhou o terror entre todos os habitantes. Ela foi mais violenta nos bairros periféricos, dizimando todos os operários que trabalhavam na estrada de ferro em Engenho Novo e todos os escravos da fazenda Macaco. O colera, ao contrário da febre amarela (epidemia de ricos e brancos) matou praticamente apenas os de categorias mais pobres, os pretos e os escravos. Os velhos foram duramente atingidos, e quase desapareceram os mendigos das ruas e praças da cidade, vitimados pelo cólera. Só em maio de 1856 a epidemia começou a amainar.

Febre amarela, escarlatina, tifo e variola atacam epidemicamente os habitantes do Rio em 1857. No ano seguinte as epidemias mais violentas registradas foram as de varíola, febre amarela e o crupe. Este levou numerosas vitimas às sepulturas.

Em 1859, foi novamente um ano de epidemias conjugadas. A febre amarela prossegue seu ciclo devastador matando so nos três primeiros meses do ano cerca de 500 pessoas. Junto a ela, a difteria atacou em todas as paróquias centrais e periféricas ceifando a vida de centenas de crianças e jovens, s6 desaparecendo entre julho e agosto, mas voltando então com nova virulencia para matar mais os pobres. Enfim a diarréia, a partir de julho seguida da epidemia de sarampo e de varíola, e após setembro da coqueluche completou o quadro terrível de flagelos e mortes do ano.

Se chovia muito nos primeiros meses do ano multiplicavam-se determinadas doenças, particularmente as desinterias e diarréias de toda origem. Mas se faltavam as chuvas a cidade tornava-se mais suja, secavam-se pântanos e mangues, exalando mal cheiro pela cidade e favorecendo outros males. $O$ ano de 1860 foi particularmente seco nos seus primeiros meses (de chuvas). Com isto a febre amarela retoma com força sua ação mortifera entre março e maio fazendo 1.252 vítimas no ano.

Os anos de 1861 a 64 não registraram epiđemias muito graves. A febre amarela quase desapareceu, a varíola matou apenas 378 pessoas, as febres 658 e a difteria e a coqueluche juntas vitimaram 904 pessoas.

Na década de 1860 o estado sanitário da cidade permanecia tenebroso. "As escavaçöes que se fizeram em quase todas as ruas da cidade para as obras da companhia de esgotos... as grandes massas de águas salobras... precedentes de lugares onde havia matérias orgânicas em decomposição... mais águas estagnadas, animais mortos e lixos em diversos pontos da cidade" (REGO, p. 116).

A mortalidade de 1865 subiu para 9.600 , com duas graves epidemias, a da varfola que matou 1.239 pessoas e a do sarampo. 
R. Htstórto, Săo Paulo, n. 127-128, p. 53-68, ago-dez/92 a jan-jul/93.

Em 1868 reapareceu com força o colera morbo, com a entrada no porto do navio Marcilio Dias vindo da Guerra do Paraguai com doentes do mar, fazendo na cidade 234 vítimas.

Após vinte anos da primeira grande epidemia da febre amarela, esta volta em fins de 1869 e em todo 1870 atingindo centenas de pessoas. Junta-se a ela novo surto de varíola e de sarampo vitimando duramente a primeira infância. Das mortes todas de $1872,9,8 \%$ foram devidas à epidemia de variola seguida do tifo, ano em que a mortalidade geral atingiu 10.378 moradores da cidade.

Mas milhares de vitimas foram registradas em 1873 de duas graves epidemias. A febre amarela novamente foi responsável por. 3.467 mortes e a variola matou 1.629, trazendo nova onda de pânico entre os habitantes.

Variola, febre amarela e sarampo continuam devastando a população nos anos seguintes, mas em 1878 s 6 a varfola foi responsável por $14,7 \%$ das mortes da cidade, ceifando 2.227 vidas.

Esta situação de idas e voltas das doenças epidemicas prossegue seu roteiro mortifero até o final do século, sem mudanças estruturais visíveis.

Em suma, nesta primeira abordagem do tema morbidade e mortalidade da cidade do Rio de Janeiro, no século XIX, podemos destacar alguns tópicos mais caracteristicos, a saber:

1. A mortalidade geral foi invariavelmente superior à natalidade a partir dos anos de 1830 e até o final do século. Os níveis da mortalidade estiveram sempre acima de $40 \%$.

Apesar de um crescimento demográfico natural negativo a populaçáo da capital do Império continuou a crescer a taxas altas. A imigração (ate 1850 sobretudo de negros da África), tanto do exterior como de outras províncias do país foi a responsável por esse crescimento contínuo;

2. A mortalidade infantil e infanto-juvenil foi em todo perfodo das mais elevadas conhecidas, provocando um verdadeiro genocídio de crianças e jovens da população;

3. As condiçōes de vida, higiene, sanitárias, de abastecimento, de moradias e de saúde pública no Rio de Janeiro são catastroficas, apesar de algumas medidas de saneamento básico, de urbanizaçăo, do organização médico-hospitalar e da modernizaçáo do sistema de enterramento dos mortos; 
MARCiIIO, Maria Luiza. Mortalidade e morbidade da cidade do Rio de Janeiro imperial.

4. A morbidade e a mortalidade tinham como fatores principais, causas endemicas e epidemicas as quais matavam em escala quase absoluta os habitantes da cidade;

5. Os anos conhecidos como de maior mortalidade foram certamente os de $1850,1855,1873,1878$ e 1883.

ABSTRACT: The article deals with the first resules of a research project about the "Social Hiswry of Health in Brazil (18th and 19th centuries)" that we are currently elaborating.

The sanianry conditions of Rio de Janeiro during the Empire and the action of the Government and of the Imperial Medical Academy were briefly outlined.

We calculated the levels of general and differential mortality (free men and slaves as well as infant mortility). The conclasion reached was that the mortality was superior to the birthrate, both anmually as well as until the end of the century. The seasonal movement showed us that during the hot and humid months the greatest number of deaths oceured.

Finally, we endeavored to mapping the chronology of the great epidemics which devasented the population of Rlo de Janciro in the past century and to becoming familiar with the deadliest chronic diseasea. Pulmoruberculose in itself was responsible for about $15 \%$ of the deaths during that period.

KEY-WORDS: martality, morbidity, demographic, Rio de Janeiro, Imperial Period. 